\title{
REFLEXÃO AMBIENTAL DO MUNICÍPIO DE PAROBÉ SOB A VISÃO DE MORADORES E DE ALUNOS DA E. E. DE ENSINO MÉDIO ENGENHEIRO PAROBÉ ${ }^{1}$
}

\author{
Luciane Krummenauer ${ }^{2}$, Paulo Edelvar Correa Peres ${ }^{3}$ \\ ${ }^{1}$ Monografia apresentada ao Curso de Educacao Ambiental, da UFSM 2011. \\ 2 Especialista em Educacao Ambiental. UFSM 2011 Santa Maria, RS. \\ ${ }^{3}$ Professor do Curso de Especializacao em Educacao Ambiental. UFSM 2011 Santa Maria, RS. \\ krumma2001@yahoo.com.br, pecperes@yahoo.com
}

\section{RESUMO}

Com o grande crescimento populacional das últimas décadas veio também o crescimento dos impactos ambientais causados por esta demanda. A educação ambiental tem papel de desenvolver uma consciência ecológica nos indivíduos, através da sensibilização ambiental relacionada com conhecimentos específicos. As questões relacionadas ao meio ambiente vão muito além de criar normas e leis para minimizar estes impactos, todos nós devemos nos sentir parte integrante como agentes dos processos que visam um desenvolvimento sustentável. 0 presente trabalho aborda como desenvolveu-se a pesquisa com alunos da Escola Estadual de Ensino Médio Engenheiro Parobé e moradores do município de Parobé. A finalidade foi verificar o que os moradores percebem sobre possíveis soluções para amenizar alguns problemas ambientais diagnosticados, assim como ampliar a compreensão dos alunos sobre aspectos ambientais do município. Constatou-se que para os moradores e para os alunos a melhor maneira de minimizar impactos ambientais é a conscientização ecológica de todos, visto que só alcançaremos resultados significativos quando conseguirmos intervir na forma de pensar, agir e perceber o mundo através da Educação ambiental.

Palavras-Chave: Educação ambiental. Alunos. Consciência ecológica. Moradores.

\section{ABSTRACT}

With the grand population growth of the latest decades, it also appeared the growth of the environmental impacts caused by this demand. The environmental Science has the role of developing an ecological conscience in the individuals, through the environmental sensibility related to specific knowledge. The issues related to the environment are farther on than creating rules and laws to reduce these impacts, all of us should feel an integral part as agents of the processes that aim at the sustainable development. The present work deals with how the research was developed with the students of the Engenheiro Parobé High School and residents of the borough of Parobé. The aim was to check what the residents see about the possible solutions to reduce some environmental problems diagnosed, and to broaden the comprehension of the students about environmental aspects of the borough. It was established that for the residents and for the students the best way to reduce the environmental impacts is the ecological 
awareness of everybody, because we will just get significant results when we may intervene in the way of thinking, acting and perceiving the world through the Environmental education.

Key-words: Environmental education. Students. Ecological conscience. Residents.

\section{INTRODUÇÃO}

O ambiente que nos cerca está constantemente sendo interpretado e reinterpretado por nós. Ele é o local das inter-relações entre a sociedade e a natureza em que o sujeito deve diagnosticar os acontecimentos reais do ambiente ao qual está inserido, assim como compreender, problematizar e solucionar os impactos da ação humana sobre a natureza levando em conta as relações que cada grupo ou indivíduo estabelecem em seus convívios sociais, históricos e culturais.

Segundo Moura (2006, p. 77) "a educação acontece como parte da ação humana de transformar a natureza em cultura, atribuindo-Ihe sentidos, trazendo-a para o campo da compreensão e da experiência humana de estar no mundo e participar da vida".

Nós, educadores, temos um papel importante e estratégico na inserção do ambiente no universo escolar; devemos estar envolvidos na tarefa de despertar, envolver e ampliar as visões sobre as realidades históricas e culturais através de experiências e informações existentes no grupo, com o intuito de que este valorize o patrimônio ambiental, refletindo, participando, manifestando-se e interagindo com a comunidade sobre as questões ambientais.

A pesquisa foi realizada tendo como pressuposto que experiências diferenciadas vividas por indivíduos no decorrer de seus cotidianos e de seus processos de escolarização e as conseqüentes transformações resultantes dessas vivências estruturem as diversas concepções de ambiente e que através delas possamos obter colaboração desses sujeitos em propostas de Educação Ambiental, assim, como nós educadores, ampliaremos nossos conhecimentos e nossas práticas pedagógicas relacionadas com este tema.

\section{REVISÃO BIBLIOGRÁFICA}

\section{A importância do ambiente para a Educação Ambiental}

Entendemos que a educação é um processo de humanização, que ocorre na sociedade humana com a finalidade explícita de tomar os indivíduos participantes do processo civilizatório e responsáveis por levá-lo adiante. Enquanto prática social, é realizada por todas as instituições da sociedade. Enquanto processo sistemático e intencional, ocorre em algumas, dentre as quais se destaca a escola. A educação escolar, por sua vez, está assentada fundamentalmente no trabalho dos professores e dos alunos (PIMENTA e ANASTASIOU, 2002, p.143).

A educação ambiental é realizada a partir da concepção que se tem de meio ambiente.

Segundo Reigota (2001, p. 14) "meio ambiente é o lugar determinado ou percebido, onde os elementos naturais e sociais estão em relações dinâmicas e em interação". Essas relações implicam processos de criação cultural e tecnológica e processos históricos e sociais de transformação do meio natural e construído.

Assim, por meio de diferentes práticas pedagógicas que aproximam os conteúdos escolares ao meio ambiente que cerca os alunos, relacionadas ao contexto histórico, cultural e social deles é 
que a escola poderá propor informações e conceitos científicos, buscando um crescente entendimento das relações entre os componentes dos ambientes, essenciais para a interpretação das questões ambientais.

Então, proporcionar o convívio do aluno com o ambiente natural, despertar seu interesse, oferecer meios para que eles analisem, reflitam e participem das discussões e decisões sobre as questões ambientais, desenvolver seu raciocínio lógico, são atividades essenciais no processo educativo, pois permitem que o aluno se torne um agente disseminador do conhecimento gerado dentro da escola, onde os alunos são os principais vínculos dessas informações.

O conhecimento gerado através da prática, da observação ou da reconstrução a partir da investigação científica é fundamental, uma vez que nossas representações regem as relações que estabelecemos com os outros e o mundo.

O ensino de ciências deve servir como meio para que "o aluno seja capaz de perceber-se integrante, dependente e agente transformador do ambiente, identificando seus elementos e as interações entre eles, contribuindo ativamente para a melhoria do meio ambiente, [Parâmetros Curriculares Nacionais: Ensino Fundamental]" (BRASIL, 1998).

Dessa maneira, para que a aprendizagem seja significativa, é primordial considerar o desenvolvimento cognitivo dos alunos, relacionado à suas experiências, sua idade, sua identidade cultural e social e os diferentes significados e valores que o ambiente pode ter para eles, pois o conhecimento científico é fundamental, mas não suficiente.

Ao estimularmos a descoberta, a crítica, junto com os alunos estaremos colhendo subsídios significativos e necessários para a construção do exercício da cidadania crítica e atuante através da Educação Ambiental.

Nesta prática educativa em que a visão de ambiente é de suma importância para o ensino de ciências, o professor constrói com o aluno uma concepção de compromisso com a sustentabilidade, o que pressupõe envolvimento com a recuperação e qualidade do ambiente.

É papel da escola despertar a conscientização ecológica nos educandos, visto que só alcançaremos resultados significativos quando conseguirmos intervir na forma de pensar, agir e perceber o mundo. Torna-se necessário que ele se perceba como parte integrante deste mundo e esteja consciente de que a ação cometida traz conseqüências positivas ou negativas a curto ou longo prazo.

“A realização de estudos do meio é motivadora para os alunos, pois desloca o ambiente de aprendizagem para fora da sala de aula. Um estudo do meio significativo pode ser realizado onde se situa a escola, [Parâmetros Curriculares Nacionais para o Ensino Médio]" (BRASIL, 1999).

No entanto, o que se percebe, de um modo geral, é que poucos professores se disponibilizam a se envolver num trabalho deste tipo, muitas vezes por comodismo ou por estarem ainda voltados para uma prática pedagógica tradicionalista que prioriza apenas os conteúdos conceituais, restritos ao trabalho em sala de aula. Esses professores não compreendem que a abordagem de temas transversais, através de um enfoque contextualizado e interdisciplinar, ao mesmo tempo que abre um leque amplo de conhecimentos para a disciplina, permite integrálos, uma vez que os situa no entrelaçamento entre as dimensões natural, social, política e econômica.

Devemos, pois, planejar de forma consistente intervenções educativas e, principalmente, executar esse planejamento de forma flexível, criando alternativas criativas que levem a escola a cumprir sua função que não é apenas transmitir informações, mas sim preparar os alunos para a vida. 


\section{A Educação Ambiental Urbana}

A maioria das pessoas do mundo atual se concentra no ambiente urbano. "A área urbana é ocupada por 84\% da população brasileira, [Censo Populacional 2010]" (IBGE, 2011).

No município de Parobé este dado ainda é maior, pois aproximadamente $94 \%$ da população se concentra no ambiente urbano.

Os ambientes urbanos, conforme Odum (1985 apud DIAS, 2004, p.227), são parasitas do ambiente rural, pois se caracterizam por produzir pouco ou nenhum alimento, poluem o ar e reciclam pouca ou nenhuma água e materiais inorgânicos.

Com o grande crescimento populacional das últimas décadas e o inchaço das áreas urbanas veio também o crescimento na exploração dos recursos não renováveis. Este inchaço das áreas urbanas fez com que as cidades tornassem-se inadequadas para o convívio saudável dos seres humanos uma vez que o crescimento desordenado e sem planejamento das cidades acarreta problemas ambientais como caos no trânsito, violência, poluição de todos os tipos, entre outros.

Segundo Unesco/Unp (1983 apud DIAS, 2004, p.228) cada habitante, em média, consome diariamente 560 litros de água, 1,8 quilos de alimentos, 8,6 quilos de combustíveis fósseis e produz cerca de 450 litros de águas sujas, 1,8 quilos de lixo e 0,9 quilos de poluentes do ar.

Os maiores impactos ambientais sobre a natureza ocorrem nas áreas urbanas. Neste contexto, a educação ambiental deve ser realizada de forma que leve em conta o centro urbano onde vive o aluno assim como a realidade ambiental em ele está inserido, pois deve haver uma estreita relação entre os trabalhos realizados e o que o aluno vivencia no seu dia-a-dia.

Segundo Jacobi $(2005$, p.384) o momento exige que a sociedade esteja mais motivada e mobilizada para assumir um caráter mais propositivo, assim como para poder questionar de forma concreta a falta de iniciativa dos governos para implementar políticas pautadas pelo binômio sustentabilidade e desenvolvimento, num contexto de crescentes dificuldades para promover-se a inclusão social.

Dessa forma, práticas pedagógicas que explorem fatos do cotidiano dos alunos são de extrema importância para que estes, a partir de sua própria realidade ambiental, ampliem suas visões e possam interferir de forma crítica e responsável nesta realidade.

O aluno precisa conhecer o significado de proteger, preservar, conservar, recuperar, degradar, termos bastante difundidos, mas escassamente compreendidos. É na exploração do ambiente urbano que esses termos podem alcançar sua total interpretação, quando a escola promove uma aprendizagem ativa, entendida como construção de novos sentidos e nexos para a vida. Trata-se de um processo que envolve transformações no sujeito que aprende e incide sobre sua identidade e posturas diante do mundo.

\section{MATERIAIS E MÉTODOS}

A metodologia utilizada no presente trabalho baseia-se na elaboração de um questionário organizado pelos alunos de uma turma de 1a série do Ensino Médio da Escola Estadual de Ensino Médio Engenheiro Parobé.

De acordo com os [Parâmetros Curriculares Nacionais para o Ensino de Ciências (BRASIL, 1998)], "os alunos têm direito a estabelecer relações entre os conteúdos mínimos de conhecimentos e a 
Vida Cidadã, através da articulação entre vários dos seus aspectos como Meio Ambiente, Ciência e Tecnologia".

No ano de 2007 os alunos de uma turma de 5ạ série da E. E. de Ensino Médio Engenheiro Parobé elaboraram um questionário (tabela 1 ) que abordava os principais aspectos do ambiente do município de Parobé. Este questionário foi respondido e aplicado pelos alunos em alguns moradores da comunidade do entorno da escola na época de setembro a outubro de 2007.

Tabela 1 - Questionário sobre os principais aspectos do município de Parobé (continua)

\begin{tabular}{|c|c|}
\hline № da questão & Questão \\
\hline 1 & $\begin{array}{l}\text { Na entrada da cidade recentemente foi colocado um outdoor com a seguinte frase: Parobé } \\
\text { capital da natureza limpa. Em relação à frase você: } \\
\qquad \begin{array}{cl}(\text { )concorda } & (\text { )concorda plenamente } \\
(\text { ) discorda } & (\text { ) discorda plenamente }\end{array}\end{array}$ \\
\hline 2 & $\begin{array}{l}\text { A praça central de Parobé é muito suja. Você: } \\
\qquad \begin{array}{l}\text { ( )concorda }(\text { )concorda plenamente } \\
\text { ( )discorda }(\text { )discorda plenamente }\end{array}\end{array}$ \\
\hline 3 & $\begin{array}{l}\text { Durante o verão, os rios que banham Parobé, são uma ótima opção de lazer. Você: } \\
\qquad \begin{array}{lll}(\text { )concorda } & (\text { )concorda plenamente } \\
(\text { )discorda } & (\text { )discorda plenamente }\end{array}\end{array}$ \\
\hline \multicolumn{2}{|l|}{ (continuação) } \\
\hline № da questão & Questão \\
\hline 4 & $\begin{array}{l}\text { Muitas ruas de Parobé possuem esgoto a céu aberto. Você: } \\
\qquad(\text { )concorda }(\text { )concorda plenamente } \\
\text { ( ) discorda }(\text { )discorda plenamente }\end{array}$ \\
\hline 5 & $\begin{array}{l}\text { A saúde em Parobé é considerada como exemplo no país. Você: } \\
\qquad \begin{array}{l}\text { ( )concorda ( )concorda plenamente } \\
\text { ( )discorda ( )discorda plenamente }\end{array}\end{array}$ \\
\hline 6 & $\begin{array}{l}\text { O trânsito em Parobé é muito desorganizado. Você: } \\
\qquad \begin{array}{l}\text { ( ) )concorda }(\text { )concorda plenamente } \\
(\text { )discorda }(\text { )discorda plenamente }\end{array}\end{array}$ \\
\hline 7 & $\begin{array}{l}\text { O Policiamento de Parobé vem realizando um ótimo trabalho na cidade. Você: } \\
\qquad \begin{array}{ll}\text { ( )concorda } & (\text { )concorda plenamente } \\
(\text { ) discorda } & (\text { ) discorda plenamente }\end{array}\end{array}$ \\
\hline 8 & $\begin{array}{l}\text { Parobé possui poucos locais para lazer. Você: } \\
\qquad \begin{array}{l}\text { ( )concorda ( )concorda plenamente } \\
\text { ( ) )discorda } \quad \text { ( ) discorda plenamente }\end{array}\end{array}$ \\
\hline 9 & $\begin{array}{l}\text { O atendimento no hospital de Parobé é de péssima qualidade. Você: } \\
\qquad(\text { )concorda }(\text { )concorda plenamente } \\
(\text { )discorda }(\text { )discorda plenamente }\end{array}$ \\
\hline 10 & $\begin{array}{l}\text { No geral, as ruas de Parobé são limpas. Você: } \\
\qquad(\text { )concorda }(\text { )concorda plenamente } \\
\text { ( )discorda }(\text { )discorda plenamente }\end{array}$ \\
\hline 11 & $\begin{array}{l}\text { O "Morro dos Gil" é a única grande área verde encontrada em Parobé. Você: } \\
\text { ( )concorda ( )concorda plenamente } \\
\text { ( )discorda } \quad(\text { )discorda plenamente }\end{array}$ \\
\hline
\end{tabular}




\begin{tabular}{|c|c|}
\hline № da questão & Questão \\
\hline 12 & $\begin{array}{l}\text { O esgoto que provém das residências de Parobé escoa para o rio dos Sinos. Esta prática é } \\
\text { natural e não causa problemas, pois a água que chega às casas é tratada. Você: } \\
\text { ( )concorda ( )concorda plenamente } \\
\text { ( ) discorda ( ) discorda plenamente }\end{array}$ \\
\hline
\end{tabular}

Passaram-se alguns anos e estes mesmos alunos agora no 10 ano do Ensino Médio no ano de 2011, a partir dos principais problemas ambientais diagnosticados através do questionário acima, elaboraram um novo questionário com intuito de verificar o que alguns moradores do entorno da escola percebem sobre possíveis soluções para amenizar estes problemas ambientais.

Cada aluno entrevistou um total de cinco moradores com idades entre 14 e 70 anos com os seguintes graus de escolaridade: Ensino Fundamental incompleto, Ensino Fundamental completo, Ensino Médio incompleto, Ensino Médio completo, graduação incompleta e graduação completa. Os questionários foram respondidos através de anotações feitas pelos próprios entrevistados no mês de outubro de 2011.

Os alunos e moradores responderam ao questionário que segue abaixo:

Conforme pesquisa realizada em 2007 os principais problemas ambientais diagnosticados foram poluição dos rios, esgoto a céu aberto, saúde precária, trânsito desorganizado, insatisfação com o trabalho dos policiais, falta de locais para lazer e a poluição das ruas. Para você quais seriam as melhores medidas a serem tomadas para solucionar estes problemas ambientais?

\section{RESULTADOS E DISCUSSÃO}

\section{Considerações sobre os resultados obtidos}

Os resultados obtidos traçam a realidade e as expectativas de uma parcela de moradores do entorno da escola e de alunos de uma turma de 1 o ano da E. E. de Ensino Médio Engenheiro Parobé do município de Parobé quanto às possíveis soluções para minimizar alguns problemas ambientais.

Para que a Educação Ambiental obtenha os resultados esperados, é necessário que os processos educativos estejam estreitamente relacionados com a realidade, pois as atividades devem ser estruturadas em torno de problemas concretos vivenciados pela comunidade. Cabe ao professor sensibilizar o aluno quanto à problemática ambiental, promover o desenvolvimento de conhecimento, de atitudes e de habilidades essenciais à preservação e melhoria da qualidade ambiental.

Cada aluno além de responder, entrevistou 5 moradores com idades entre 14 e 70 anos. Dos 132 entrevistados, $10,6 \%$ possuem ensino fundamental incompleto, $21,96 \%$ ensino fundamental completo, $26,51 \%$ ensino médio incompleto, $20,45 \%$ possuem ensino médio completo, $9,84 \%$ ensino superior incompleto e $9,09 \%$ possuem superior completo.

Os resultados foram os seguintes:

Dos 132 alunos e moradores entrevistados 52\% apontam como a maneira mais eficaz de reduzirmos os impactos ambientais é a conscientização ecológica da população. 
O morador de 26 anos do bairro Guarujá disse o seguinte: "Estes problemas ambientais não são só um caso para políticas públicas, mas para o próprio povo que precisa ser consciente antes de exigir. Se cada um souber seu papel de cuidar do meio ambiente, vai poder cobrar depois".

A problemática ambiental encontra-se cada vez mais presente no cotidiano da sociedade em geral, seja através da divulgação nos meios de comunicação, seja devido a nítidas alterações da paisagem e climáticas nos diversos ambientes.

Podemos constatar que mais da metade dos moradores e alunos possuem consciência, conhecimento e compreensão da existência de problemas ambientais que afetam a natureza e que estes se devem a má utilização e conservação dos recursos naturais.

A população de Parobé cresceu de um pouco mais de 4000 (quatro mil) habitantes no início dos anos 80 para 51502 hab. (IBGE, 2011).

O processo de urbanização consiste no deslocamento de um grande contingente de pessoas que saem da área rural para os centros urbanos. As alterações no ambiente surgem nas cidades como conseqüência das relações do homem com a natureza, e tornam-se ainda mais graves em áreas mais densamente ocupadas.

O acelerado crescimento urbano, a falta de planejamento na construção das cidades e suas atividades econômicas, articuladas com o espaço urbano acarretam alterações introduzidas no espaço construído. As mais comuns são: retirada da cobertura vegetal, construção de novas formas de relevo, aumento da edificação, acréscimo de escoamento superficial, rugosidade da superfície, lançamento concentrado e acúmulo de partículas e gases na atmosfera e produção de energia artificial, modificando elementos naturais, como o clima, o ar, a vegetação, o relevo e a água, além de outros problemas sócio-ambientais comuns às cidades brasileiras.

Boa parte de entrevistados, $26,51 \%$, citam que o dinheiro público deveria ser melhor administrado pelos políticos e que estes também deveriam desempenhar melhor suas funções. Cerca de $22 \%$ acreditam que para solucionar os problemas ambientais é fundamental que os políticos sejam mais honestos e que a corrupção diminua. Conforme estes resultados observados, podemos concluir que uma grande parcela dos alunos e dos moradores estão insatisfeitos, de um modo geral, com as atitudes dos nossos governantes. Este descontentamento se deve ao atual desprestígio da classe política perante a sociedade, com muitos escândalos de corrupção envolvendo políticos que procuram interesses pessoais frente ao bem comum. Outro fator é que atualmente a mídia publica estes escândalos envolvendo corrupção política que antes provavelmente ocorriam e somente não eram denunciados.

Em torno de $22 \%$ dos entrevistados acham que o governo deveria investir mais de um modo geral.

Investimentos específicos na educação ambiental da população através de palestras e projetos ministrados por profissionais habilitados, é o que $17 \%$ citam como solução.

O morador de 22 anos que reside no bairro Emancipação, quanto às melhores medidas para solucionar a problemática ambiental, disse que a solução seria: "Investir mais em palestras sobre os riscos da poluição. Criar projetos ecológicos, sendo eles formados por escolas, empresas, secretarias municipais e comunidade".

Neste contexto, entendemos que projetos que estimulam a consciência ambiental são de extrema importância para que a população se sinta parte integrante do meio ambiente e busque valores que a conduzam a uma convivência harmoniosa com a natureza. 
Cerca de $12 \%$ dos alunos e moradores acreditam que maior fiscalização, aplicação de multas e punições mais severas para quem degrada o meio ambiente seria a melhor medida para minimizar os problemas ambientais.

Um morador de 20 anos do bairro Alexandria em resposta ao questionário aplicado disse o seguinte: "Deveria haver multas para quem põe lixo no chão. Assim a população de conscientizaria."

Entendemos que a legislação ambiental assegura juridicamente que o meio ambiente seja protegido. Mas, as questões relacionadas ao meio ambiente vão muito além de criar normas e leis para minimizar os impactos ambientais, todos nós devemos nos sentir como agentes dos processos que visam um desenvolvimento sustentável, pois a sustentabilidade do planeta depende da consciência e da atitude ecológica de todos.

Um pequeno percentual, 5\%, crêem que a melhor remuneração dos professores e policiais minimizaria a problemática ambiental.

Em torno de $12 \%$, é o percentual de entrevistados que acredita que a solução seria mais investimentos na saúde.

A partir dos resultados observados que abordam como solução investimentos do governo em diversas áreas, concluímos que a população entende a necessidade de mais atenção dos governantes quanto às verbas destinadas às políticas públicas que beneficiam projetos que sensibilizam ecologicamente os indivíduos, assim como aos serviços básicos como saúde e segurança, entre outros.

O educador deve estar atento para propor conteúdos e atividades que possibilitem ao aluno aprender pela ação. $O$ processo ensino-aprendizagem se constitui dentro das interações que vão se dando nos diversos contextos sociais (DEMO, 1995, p. 63).

Neste contexto, é essencial formular uma educação crítica e inovadora, voltada para a transformação social, tendo em vista que os recursos naturais se esgotam e que o principal responsável por isso é o próprio homem. Que nós professores devemos abordar sobre a importância da percepção das relações de interdependência dos sistemas de sustentação da vida, da preservação do meio ambiente e da manutenção da qualidade de vida da população através de atividades adequadas que envolvam aspectos da problemática ambiental local.

Os alunos tiveram a oportunidade de relacionar fatos que ocorrem no ambiente em que estão inseridos com o conteúdo visto em aula. É esta a prática adequada para que os alunos aprendam a interpretar e compreender o que está a sua volta e as relações estabelecidas ali.

A necessidade de abordarmos temas ambientais, tanto com alunos como com os moradores decorre do momento atual em que vivemos e das múltiplas possibilidades que temos de modificá-lo e de transformá-lo em um espaço no qual interagem comunidade, escola e natureza. Uma educação para cidadania implica em liberdade responsável e participação política. Assim nossa argumentação visa promover e reforçar as práticas educativas que se interligam nas diversas áreas do conhecimento, posto que a consciência ambiental ultrapassa esses limites e o conhecimento exige um esforço de todos e a elaboração de novas propostas pedagógicas que apontem um novo caminho no desenvolvimento do conhecimento, da capacidade de avaliar e na participação dos alunos.

O tema educação ambiental vai muito além de uma simples disciplina. Envolve discussões de novos valores, de novos comportamentos, buscando preparar as pessoas a refletirem entre si mesmas e a participarem do processo de transformação social (BÖER, 1993, p.96). 


\section{CONCLUSÃO}

Para estar em sintonia com os desafios atuais da sociedade, é necessário que as questões que interferem na vida dos alunos e com as quais eles se confrontam no dia-a-dia sejam tratadas na escola. Por isso, há um grande desafio para a escola e a educação que é o de trabalhar com atitudes, com a formação de valores, habilidades e procedimentos. Comportamentos corretos, em relação ao meio ambiente, serão aprendidos envolvendo ações práticas e construindo novas perspectivas nas quais o aluno possa intervir e participar na transformação da realidade. Entendese que existem dificuldades, falta de tempo, espaço, conteúdos a serem cumpridos, mas todos nós concordamos que aquilo que relacionamos à realidade é por nós facilmente assimilado e entendido.

$\mathrm{Na}$ medida que a relação entre o meio ambiente e a escola assume um papel cada vez mais desafiador, chamamos a atenção da comunidade escolar sobre a importância dos ambientes, para que os alunos adquiram conhecimentos essenciais à compreensão e à resolução das transformações provocadas pela ação humana e desenvolvam medidas e atitudes necessárias para proteger e melhorar o meio ambiente.

Portanto, todos nós devemos nos tornar sujeitos comprometidos com o ideário ambiental; devemos ser intérpretes e facilitadores de novas experiências e aprendizagens que nos levem a modificar nossas atitudes e nossos hábitos em relação à questão ambiental e é a educação que torna isso realidade. A educação ambiental inserida na comunidade escolar, não como parte restrita ao ensino de ciências, mas como um processo educativo, leva o individuo a pensar com clareza sobre suas atitudes e de seus semelhantes, em relação ao meio que os cerca, garantindo assim a utilidade dos recursos (água, solo, fauna e flora) de forma consciente sem degradar a natureza.

A execução da pesquisa de campo proporcionou maior interação entre professor - aluno e alunoaluno, uma vez que tudo foi desenvolvido em conjunto.

Através da pesquisa de campo associada à teoria em sala de aula percebeu-se que os alunos tiveram uma aprendizagem mais eficaz e adquiriram fundamentos para analisar a realidade vivida, de forma consciente e crítica, partindo da comunidade onde estão inseridos para escalas geográficas regionais e globais.

A partir dos questionários respondidos sobre questões ambientais os moradores tiveram a oportunidade de refletir e ampliar as percepções que envolvem a problemática ambiental do município de Parobé.

Concluímos que a realização do trabalho contribuiu para o avanço do conhecimento do aluno e também para o crescimento pessoal de todos os envolvidos. Pois, o conhecimento do meio em que vive o aluno, a aptidão de identificar e solucionar problemas ambientais, associados ao compromisso com a transmissão de valores vivenciados na escola, fazem com que este desenvolva a capacidade de intervir e transformar a realidade, construindo novas possibilidades que inclua a justiça social, a ética e a cidadania. 


\section{REFERÊNCIAS BIBLIOGRÁFICAS}

BÖER, N. Educação Ambiental em Escolas de 1o grau.Santa Maria: UFSM, 1993.

BRASIL. Secretaria de Educação Fundamental (SEF), Ministério da Educação (MEC). Parâmetros Curriculares Nacionais: ciências. Brasília. MEC/SEF, 1998.

. Ministério da Educação (MEC), Secretaria da Educação Média e Tecnológica (Semtec). Parâmetros Curriculares Nacionais para o Ensino Médio. Brasília. MEC/Semtec, 1999.

DEMO, P. Avaliação Qualitativa: Polêmicas do nosso tempo. 5.ed. Campinas, SP: Autores associados, 1995.

DIAS, G. F. Educação Ambiental: princípios e práticas. 9.ed. São Paulo: Gaia, 2004.

2000. . Pedagogia da indignação - cartas pedagógicas e outros escritos. São Paulo: UNESP, 134 p.,

IBGE. Geografia do Brasil: Grande Região Sul. 2 ed. Rio de Janeiro. 1986. v.4.

. In: CENSO populacional 2010. Disponível em: http://www.ibge.gov.br/home/ presidencia/noticias/noticia_visualiza.php?id_noticia=1766>. Acesso em: 13 nov. 2011.

JACOBI, P. R. Educação Ambiental: o desafio da construção de um pensamento crítico, complexo e reflexivo. Educação e Pesquisa. São Paulo, v.31, n. 2, p. 233-250, maio/ago. 2005.

MOSMANN, L. Parobé, uma história a ser contada. Parobé. 1999.

MOURA, I. C. C. Qual Educação Ambiental? Elementos para um debate sobre educação ambiental e extensão rural. Agroecologia e desenvolvimento rural sustentável. v. 2. n. 2. p. 43-51, abr./jun. 2001.

PIMENTA, S. G.; ANASTASIOU, L. das G. C. Docência no ensino superior. São Paulo: Cortez, 2002.

PROTEGER- Programa Técnico para Gerenciamento da Região Metropolitana de Porto Alegre. Cobertura vegetal do município de Parobé- RS. V.6., Porto Alegre: CPRM/METROPLAN, 1994.

RAMBO, B.\& Pe. S.J. A fisionomia do Rio Grande do Sul. 2.ed. Porto Alegre: Selback, 1956.

REIGOTA, M. Meio Ambiente e Representação Social. São Paulo: Cortez, 2001. 